\title{
A genome-wide detection of copy number variations using SNP genotyping arrays in swine
}

\author{
Jiying Wang ${ }^{1,2 \dagger}$, Jicai Jiang ${ }^{1 \dagger}$, Weixuan Fu', Li Jiang ${ }^{1}$, Xiangdong Ding ${ }^{1}$, Jian-Feng Liu ${ }^{1 *}$ and Qin Zhang ${ }^{1 *}$
}

\begin{abstract}
Background: Copy Number Variations (CNVs) have been shown important in both normal phenotypic variability and disease susceptibility, and are increasingly accepted as another important source of genetic variation complementary to single nucleotide polymorphism (SNP). Comprehensive identification and cataloging of pig CNVs would be of benefit to the functional analyses of genome variation.

Results: In this study, we performed a genome-wide CNV detection based on the Porcine SNP60 genotyping data of 474 pigs from three pure breed populations (Yorkshire, Landrace and Songliao Black) and one Duroc $\times$ Erhualian crossbred population. A total of 382 CNV regions (CNVRs) across genome were identified, which cover $95.76 \mathrm{Mb}$ of the pig genome and correspond to $4.23 \%$ of the autosomal genome sequence. The length of these CNVRs ranged from 5.03 to $2,702.7 \mathrm{~kb}$ with an average of $250.7 \mathrm{~kb}$, and the frequencies of them varied from 0.42 to $20.87 \%$. These CNVRs contains 1468 annotated genes, which possess a great variety of molecular functions, making them a promising resource for exploring the genetic basis of phenotypic variation within and among breeds. To confirmation of these findings, 18 CNVRs representing different predicted status and frequencies were chosen for validation via quantitative real time PCR (qPCR). Accordingly, 12 (66.67\%) of them was successfully confirmed.

Conclusions: Our results demonstrated that currently available Porcine SNP60 BeadChip can be used to capture CNVs efficiently. Our study firstly provides a comprehensive map of copy number variation in the pig genome, which would be of help for understanding the pig genome and provide preliminary foundation for investigating the association between various phenotypes and CNVs.
\end{abstract}

Keywords: Copy number variations, Genetic variation, SNP arrays, Quantitative real time PCR, Pig

\section{Background}

Copy number variation (CNV) is defined as a segment of DNA that is $1 \mathrm{~kb}$ or larger and present at a variable copy number in comparison with a reference genome [1,2]. So far, CNV has gained considerable interests as a source of genetic variation in many species. Extensive studies have been performed to identify and map CNV in humans [13], model organisms [4-6] and domestic animals [7-11]. Compared with the most frequent SNP marker, CNVs cover wider genomic regions in terms of total bases involved and have potentially larger effects by changing

\footnotetext{
* Correspondence: liujf@cau.edu.cn; qzhang@cau.edu.cn

${ }^{\dagger}$ Equal contributors

'Key Laboratory of Animal Genetics, Breeding and Reproduction, Ministry of Agriculture, National Engineering Laboratory for Animal Breeding, College of Animal Science and Technology, China Agricultural University, Beijing 100193, China

Full list of author information is available at the end of the article
}

gene structure and dosage, alternating gene regulation, exposing recessive alleles and other mechanisms [12,13]. CNVs have been shown to be important in both normal phenotypic variability and disease susceptibility $[1,13,14]$ and association studies of CNVs and diseases have become popular in human [15-17]. Additionally, in animals, phenotype variations caused by CNVs were also observed, for instance, the white coat phenotype in pigs caused by the copy number variation of the KIT gene $[18,19]$ and the pea-comb phenotype in chickens caused by the copy number variation in intron 1 of the SOX 5 gene [20]. These demonstrate that CNVs can be considered as promising markers for some economically important traits or diseases in domestic animals. Thus, comprehensive identification and cataloging of CNVs will greatly benefit functional analyses of genome variation.

Although pig is one of the most economically important worldwide livestock as well as a suitable animal

\section{Biomed Central}


model for human disease, few studies are focused on investigating $\mathrm{CNV}$ in pig compared to other species [4$8,21,22]$. So far, there are merely two studies on pig CNV detection reported. Fadista et al. [9] addressed the first account of CNV survey (37 CNVRs) among 12 Duroc boars using a custom tiling oligonucleotide array CGH approach. Ramayo-Caldas et al. [10] identified 49 CNVRs in 55 animals from an Iberian $x$ Landrace cross using Porcine SNP60 BeadChips. Previous studies at genome scale suggest that CNVs comprise up to $~ 12 \%$, $4 \%$ and $4.6 \%$ of human[2], dog[21] and cattle [8] genome sequence, respectively. Compared with abundance of CNVRs detected in other species, CNVs detected in pig is far from saturation.

Currently, CNVs can be identified using different technological approaches. Two major platforms, i.e., comparative genomic hybridization $(\mathrm{CGH})$ array and SNP genotyping array, were extensively compared by Redon et al. [2]. Although CGH array based approach has excellent performance in signal-to-noise ratios, the SNP genotyping array has the advantage of performing both genome-wide association studies (GWAS) and $\mathrm{CNV}$ detection [23]. CGH arrays report only relative signal intensities, whereas SNP arrays collect normalized total signal intensity (Log $R$ ratio - LRR) and allelic intensity ratios (B allele frequency - BAF) which represent overall copy numbers and allelic contrasts [23]. SNP arrays use less sample per experiment compared to CGH arrays, and it is a cost effective technique which allows users to increase the number of samples tested on a limited budget [24]. Nowadays, SNP arrays have been routinely used for CNV detection in human and other organisms $[2,8,10,25]$, and manufacturers of SNP genotyping arrays have incorporated non-polymorphic markers into their SNP genotyping arrays to improve the coverage of SNP arrays for CNV analyses [26].

In the present study, using the PennCNV software [27], a genome-wide CNV detection based on the Porcine SNP60 BeadChip was performed in a large sample of 474 pigs from four breed populations with different genetic background. Our study firstly provides a comprehensive map of CNVs in the pig genome, which would be helpful for understanding the genomic variation in the pig genome and provide preliminary foundation for investigating the association between various economically important phenotypes and CNVs.

\section{Results}

\section{Genome-wide detection of CNVs}

Overall, 4,279 CNVs were assessed by PennCNV on 18 pairs of autosomal chromosomes. The average number of CNVs per individual was 9.03. By aggregating overlapping CNVs, a total of 382 CNVRs (Additional file 1; Table S1) across genome were identified, which cover
$95.76 \mathrm{Mb}$ of the pig genome and correspond to $4.23 \%$ of the autosomal genome sequence. Among these CNVRs, we found 296 loss, 34 gain and 52 both (loss and gain within the same region) events. The length of these CNVRs ranged from 5.03 to $2,702.7 \mathrm{~kb}$ with a mean of $250.7 \mathrm{~kb}$ and a median of $142.9 \mathrm{~kb}$. The frequencies of these CNVRs ranged from 0.42 to $20.87 \%$. In particular, there were 46 CNVRs with frequency $>5 \%$, and 8 CNVRs $>10 \%$. Figure 1 summarizes the location and characteristics of all CNVRs on autosomal chromosomes. It is obvious that these CNVRs are not uniformly distributed among different chromosomes. The proportion of CNVRs on the 18 pairs of autosomal chromosomes varies from $2.36-12.04 \%$. Chromosome 13 harbors the greatest number (46) of CNVRs, whereas chromosome 12 has the densest CNVRs with an average distance of $1,226.94 \mathrm{~kb}$ between CNVRs.

In this study, samples of four populations, including 119 Yorkshire pigs, 13 Landrace pigs, 15 Songliao Black pigs and 327 the Duroc $\times$ Erhualian crossbred pigs, were used. Large difference of CNVR numbers were found among the four populations (Table 1). In the Duroc $x$ Erhualian crossbred, we identified 239 CNVRs, which comprised $62.57 \%$ of the total CNVRs detected herein. In Yorkshire, $178 \mathrm{CNVRs}$ were detected, corresponding to nearly half of the total number $(46.60 \%)$, while only $89(23.30 \%)$ and 101 (26.44\%) CNVRs were found in Landrace and Songliao Black, respectively. 248 unique CNVRs, i.e., CNVRs detected only in one population, were detected, including 184, 57, 3 and 4 in Duroc $x$ Erhualian crossbred, Yorkshire, Landrace and Songliao Black, respectively.

\section{Gene content of pig CNVRs}

Totally, 1,468 genes within the identified CNVRs were retrieved from the Ensembl Genes 64 Database using the BioMart data management system [28], including 1,322 protein-coding genes, 80 miRNA, 29 pseudogenes, 29 snoRNA, 40 snRNA, 11 rRNA, six miscRNA and one retrotransposed gene (Additional file 1; Table S2). These genes are distributed in $282(73.8 \%)$ CNVRs, while the other 100 CNVRs do not contain any annotated genes.

In order to provide insight into the functional enrichment of the CNVs, Gene Ontology (GO) [29] and Kyoto Encyclopedia of Genes and Genomes (KEGG) [30] pathway analyses were performed with the DAVID bioinformatics resources [31]. The GO analyses revealed 119 GO terms (Additional file 1: Table S3), of which 23 were statistically significant after Benjamini correction. And the significant GO terms were mainly involved in sensory perception of smell or chemical stimulus, olfactory receptor activity, G-protein coupled receptor protein signaling pathway, cell surface receptor linked signal transduction, and other basic metabolic processes. There 


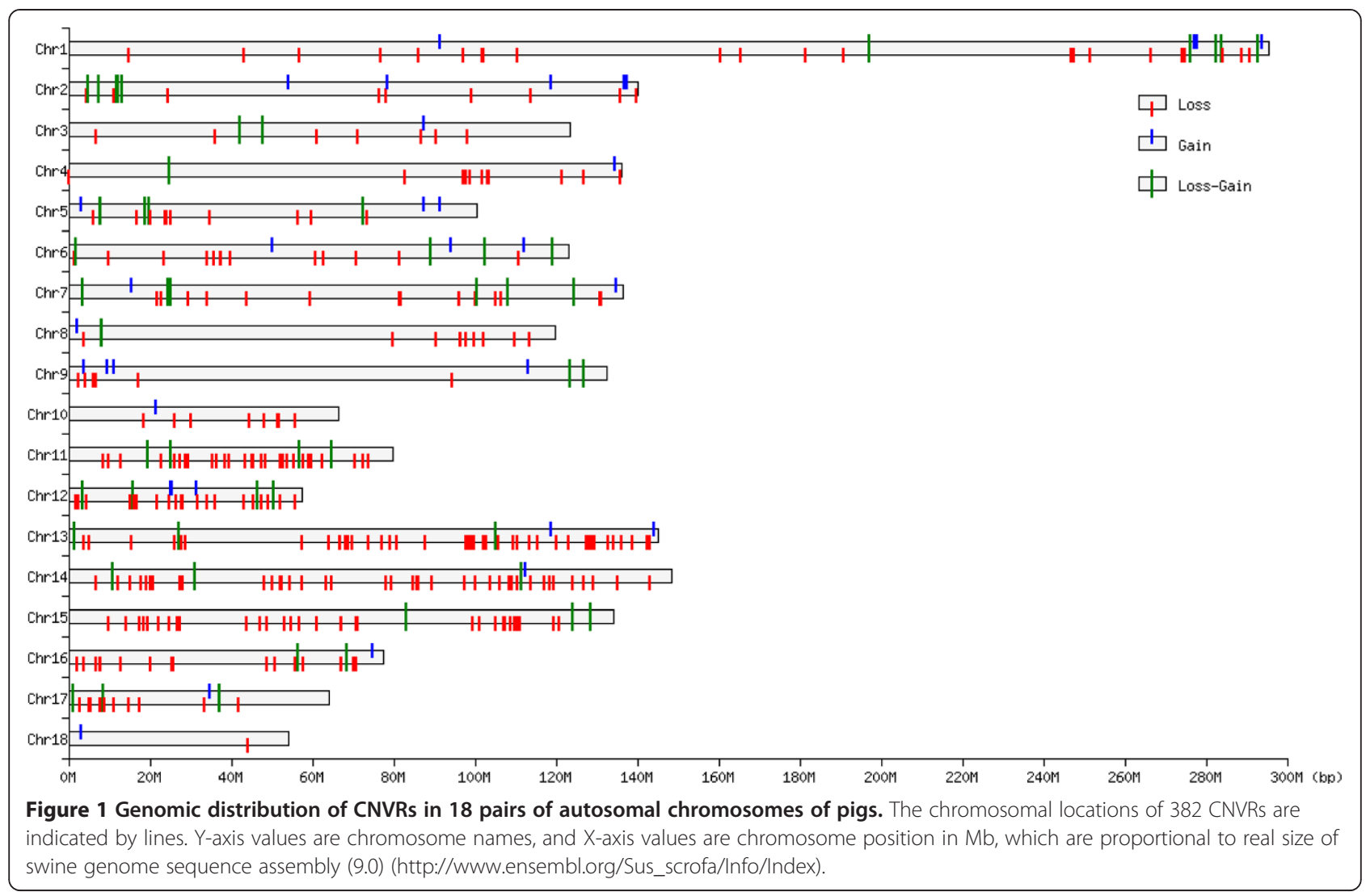

were also some enriched charts with marginal significance, which were involved in antigen processing and presentation, MHC class II protein complex, innate immune response and adaptive immune response. The KEGG pathway analyses indicated that the genes in the CNVRs were enriched in eight pathways (Additional file 1: Table S4), of which six were statistically significant after Benjamini correction, i.e., olfactory transduction, systemic lupus erythematosus, linoleic acid metabolism, drug metabolism, arachidonic acid metabolism, and metabolism of xenobiotics by cytochrome P450.

Additionally, 360 QTLs (Additional file 1: Table S5), affecting a wide range of traits, such as growth, meat

Table 1 Sample sizes and the CNVR numbers detected in the four populations

\begin{tabular}{cccc}
\hline Breed & Sample size & $\begin{array}{c}\text { CNVRs } \\
\text { number }^{\text {a }}\end{array}$ & $\begin{array}{c}\text { Unique } \\
\text { CNVRs }^{\mathbf{b}}\end{array}$ \\
\hline Yorkshire & 119 & 178 & 57 \\
Landrace & 13 & 89 & 3 \\
Songliao Black & 15 & 101 & 4 \\
Duroc $\times$ Erhualian crossbred & 327 & 239 & 184 \\
Total & 474 & 382 & 248 \\
\hline
\end{tabular}

${ }^{a}$ CNVRs number means the total number found in one breed.

${ }^{\mathrm{b}}$ Unique CNVR means CNVR only detected in one breed. quality, reproduction, immune capacity and disease resistance, were found in 16 CNVRs by comparing the overlapping of CNVRs with QTLs in the pig QTLdb (Jan 2, 2011, (http://www.animalgenome.org/cgi-bin/ QTLdb/SS/index)).

\section{CNV validation by $\mathrm{qPCR}$}

Quantitative real time PCR (qPCR) was used to validate 18 CNVRs chosen from the 382 CNVRs detected in the study. These 18 CNVRs represent different predicted status of copy numbers (i.e., loss, gain and both) and different CNVR frequencies (varied from 0.84 to $18.57 \%$ ). A total of 37 qPCR assays (Additional file 1: Table S6), i. e. two or three for every CNVR, were performed. Out of the $37 \mathrm{qPCR}$ assays, 21 (56.76\%) were in agreement with prediction by PennCNV. When counting the CNVRs, 12 (66.6\%) out of the 18 CNVRs (Table 2) had positive qPCR confirmations by at least one PCR assay. The average frequency and size of the 12 confirmed CNVRs were $4.6 \%$ and $295.5 \mathrm{~kb}$ respectively, which were smaller than those of the six unconfirmed ones $(8.2 \%$ and $1,034.8 \mathrm{~kb}$, respectively) (Additional file 1: Table S6).

For the CNVRs with low frequencies we tested all the positive samples, while for the CNVRs with high frequencies we tested part of them. Furthermore, a certain number of random negative samples were tested as 
Table 2 Results of quantitative real-time PCR analysis of the 12 confirmed CNVRs

\begin{tabular}{|c|c|c|c|c|c|c|c|c|c|c|c|c|c|c|}
\hline \multirow{2}{*}{$\begin{array}{l}\text { CNVR } \\
\text { No. }\end{array}$} & \multirow{2}{*}{ Chr. } & \multirow{2}{*}{ Start ${ }^{\mathrm{a}}$} & \multirow[t]{2}{*}{ End $^{a}$} & \multirow{2}{*}{$\begin{array}{c}\text { Primer } \\
\text { IID }\end{array}$} & \multicolumn{4}{|c|}{ Positive samples } & \multicolumn{4}{|c|}{ Negative samples } & \multirow{2}{*}{ validated } & \multirow[t]{2}{*}{ Genes } \\
\hline & & & & & Frequency & Type & $\begin{array}{c}\text { Number } \\
\text { of } \\
\text { samples }\end{array}$ & $\begin{array}{c}\text { Confirmed } \\
\text { samples }\end{array}$ & $\begin{array}{l}\text { Confirmed } \\
\text { rate }\end{array}$ & $\begin{array}{c}\text { Number } \\
\text { of } \\
\text { sample }\end{array}$ & $\begin{array}{c}\text { Confirmed } \\
\text { samples }\end{array}$ & $\begin{array}{l}\text { Confirmed } \\
\text { rate }\end{array}$ & & \\
\hline \multirow[t]{2}{*}{6} & 1 & 91513835 & 91584145 & $17-2$ & 0.0148 & gain & 7 & 7 & 1.0000 & 5 & 0 & 0.0000 & Yes & - \\
\hline & & & & $17-8$ & & & 7 & 0 & - & 5 & 0 & - & No & - \\
\hline \multirow[t]{2}{*}{11} & 1 & 160653704 & 160713406 & $4-1$ & 0.0675 & loss & 32 & 32 & 1.0000 & 15 & 1 & 0.0667 & Yes & - \\
\hline & & & & $4-4$ & & & 32 & 32 & 1.0000 & 15 & 1 & 0.0667 & Yes & - \\
\hline \multirow[t]{2}{*}{20} & 1 & 274307988 & 274570232 & $5-3$ & 0.0274 & loss & 13 & 0 & - & 11 & 0 & - & No & C5 \\
\hline & & & & $5-7$ & & & 13 & 12 & 0.9200 & 11 & 2 & 0.18 & Yes & TRAF1 \\
\hline \multirow[t]{2}{*}{22} & 1 & 276291234 & 276800847 & $3-1$ & 0.0738 & both & 35 & 31 & 0.8857 & 11 & 1 & 0.0909 & Yes & ORs \\
\hline & & & & $3-5$ & & & 35 & 35 & 1.0000 & 15 & 6 & 0.4000 & Yes & \\
\hline \multirow[t]{2}{*}{161} & 14 & 52620825 & 52720705 & $6-3$ & 0.0211 & loss & 10 & 10 & 1.0000 & 11 & 8 & 0.7273 & Yes & - \\
\hline & & & & $6-6$ & & & 10 & 10 & 1.0000 & 11 & 8 & 0.7273 & Yes & - \\
\hline \multirow[t]{2}{*}{259} & 2 & 4834400 & 5424602 & $7-3$ & 0.0759 & both & 18 & 16 & 0.8889 & 12 & 6 & 0.5000 & Yes & EFEMP2 \\
\hline & & & & $7-5$ & & & 36 & 31 & 0.8611 & 12 & 6 & 0.5000 & Yes & DPF2 \\
\hline \multirow[t]{3}{*}{276} & 2 & 137644872 & 137915976 & $15-4$ & 0.0928 & gain & 8 & 0 & - & 4 & 0 & - & No & ORs \\
\hline & & & & $15-5$ & & & 38 & 26 & 0.6842 & 19 & 9 & 0.4737 & Yes & \\
\hline & & & & $15-6$ & & & 8 & 7 & 0.8750 & 4 & 1 & 0.2500 & yes & \\
\hline \multirow[t]{2}{*}{285} & 3 & 87641425 & 87711895 & $16-2$ & 0.0422 & gain & 20 & 18 & 0.9000 & 12 & 8 & 0.6666 & Yes & - \\
\hline & & & & $16-5$ & & & 20 & 19 & 0.9500 & 18 & 10 & 0.5556 & Yes & - \\
\hline \multirow[t]{2}{*}{314} & 5 & 59744851 & 60461526 & $13-1$ & 0.0084 & loss & 4 & 3 & 0.7500 & 12 & 0 & 0.0000 & Yes & CD4 \\
\hline & & & & $13-5$ & & & 4 & 3 & 0.7500 & 8 & 0 & 0.0000 & Yes & GAPDH \\
\hline \multirow[t]{2}{*}{325} & 6 & 37641317 & 38387857 & $8-2$ & 0.0211 & loss & 10 & 10 & 1.0000 & 8 & 2 & 0.2500 & Yes & $F T L$ \\
\hline & & & & $8-5$ & & & 10 & 10 & 1.0000 & 8 & 2 & 0.2500 & Yes & IRF3 \\
\hline \multirow[t]{2}{*}{344} & 7 & 29445530 & 29634684 & $9-4$ & 0.0105 & loss & 5 & 0 & - & 7 & 0 & - & No & - \\
\hline & & & & $9-6$ & & & 5 & 5 & 1.0000 & 16 & 10 & 0.6250 & Yes & - \\
\hline \multirow[t]{2}{*}{373} & 9 & 4203824 & 4364337 & $2-2$ & 0.0928 & loss & 28 & 28 & 1.0000 & 17 & 4 & 0.2353 & Yes & ORs \\
\hline & & & & $2-7$ & & & 29 & 29 & 1.0000 & 17 & 2 & 0.1176 & Yes & \\
\hline Mean & & & & & & & & & 0.9269 & & & 0.3182 & & \\
\hline
\end{tabular}

a The Sus scrofa assembly (9.0) (http://www.ensembl.org/Sus_scrofa/Info/Index) was used to indicate the position of the CNVRs.

negative control for every CNVR. For the positive samples of the 12 confirmed CNVRs, the proportions of confirmed samples varied from $68.42 \%$ to $100 \%$, with an average of $92.69 \%$. For the negative samples of the 12 confirmed CNVRs, the proportions of confirmed samples (i.e. false negative) varied from 0 to $72.73 \%$, with an average of $31.82 \%$ (Table 2). Additionally, the copy numbers in some CNVRs varied among individuals. For example, we found one copy loss and different copy gain (three to six copies) in CNVR22 (Figure 2), and one and two copies loss in CNVR373 (Figure 3).

\section{Discussion}

In our study, among the four populations, the largest number of total CNVRs and unique CNVRs were detected in the Duroc $\times$ Erhualian crossbred population. In addition to the larger sample size, another important reason is that this population has special genetic background. Particularly, Erhualian is one famous Chinese indigenous breed. Many previous studies have indicated that Chinese indigenous pig breeds have different genetic background with western commercial breeds, such as Duroc, Landrace and Yorkshire [32-35]. Therefore, there are breed-specific CNVs in pigs, which is consistent with the report in cattle [7]. The differences of CNV among breeds supported that some CNVs are likely to generate independently in breeds and therefore, likely contribute to breed differences.

We compared our results with two previous reports on pig CNVs (Additional file 1: Table S7). Ramayo-Caldas et al. [10] firstly used the Porcine SNP60 BeadChip data of 55 animals from an Iberian $x$ Landrace cross to identify CNVs in pig, and detected 49 CNVRs by at least two programs of cnvPartition (Illumina Inc.), PennCNV [27] 


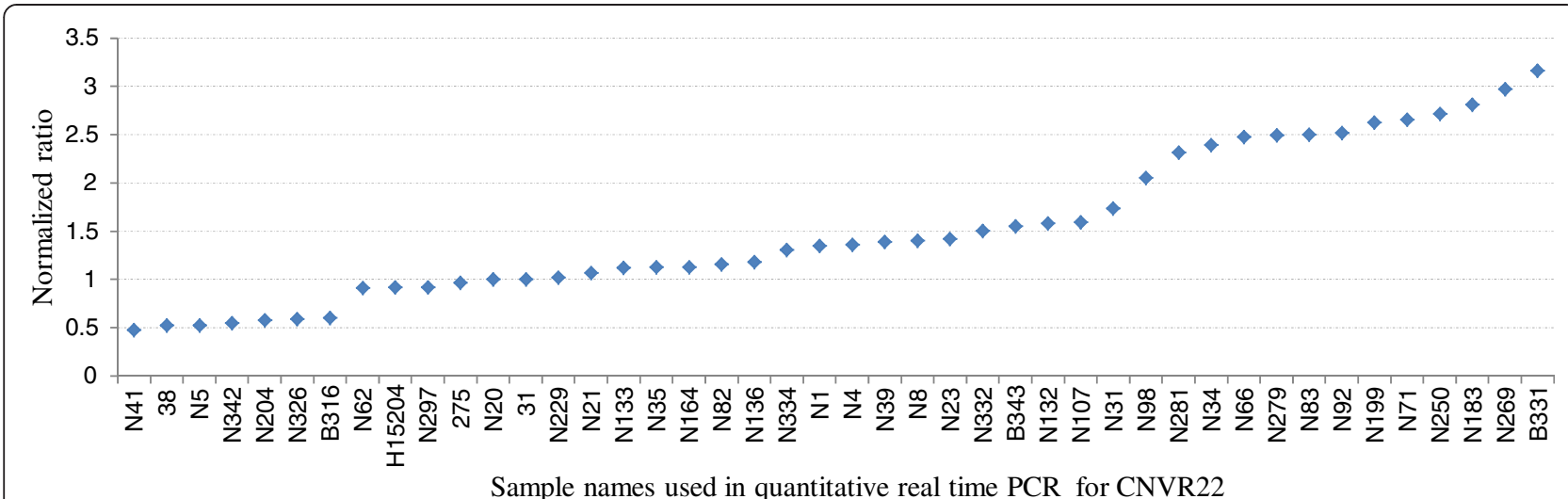

Figure 2 Normalized ratios (NR) obtained by Quantitative real time PCR (qPCR) for CNVR22. Y-axis shows the NR values obtained by $q P C R$, and $\mathrm{X}$-axis represents the sample name of the detected 33 positive and 11 negative control samples. Samples with NR about 1 denote normal individuals (two copy), samples with NR about 0.5 denote one copy loss individuals (one copy), and samples with NR about 1.5 or more denote copy number gain individuals ( $\geqq$ three copy).

and GADA [36]. Twenty-two out of the 49 CNVRs (44.9\%) are identical or overlapped with our results. Using the custom tiling oligonucleotide array CGH approach, Fadista et al. [9] addressed 37 CNVRs on the SSC4, 7, 14, and 17 of the preliminary assembly of pig genome among 12 Duroc boars. However, only one CNVR of them was found overlapping with our results.

The potential reasons for the different results between this study and the other two studies lie in the following aspects. Firstly, the study population differed in terms of size and genetic background in different studies. A much larger sample size with broader genetic background (three pure breeds and one crossbred population) were included in this study in comparison with the other two studies, where only one breed or crossbreed (different from ours) with very small sample size were involved.
Secondly, different platforms, SNP genotyping array and $\mathrm{CGH}$ array, are different in the calling technique, resolution difference and genome coverage which contribute to the discrepancy of CNVs detected. Thirdly, previous studies showed that genomic waves have a significant interfere with accurate CNV detection [8,37]. Genomic wave refers to the patterns of signal intensities across all chromosomes, where different samples may show highly variable magnitude of waviness. In our study, the genomic waves were adjusted using the -gcmodel option, while it was not in the study of Ramayo-Caldas et al. [10]. The issue of low overlapping rates between different reports was also encountered in CNV studies in other mammal $[7,8,38,39]$.

A large amount annotated genes (1,468 Ensembl genes) are located in the 382 identified CNVRs. The

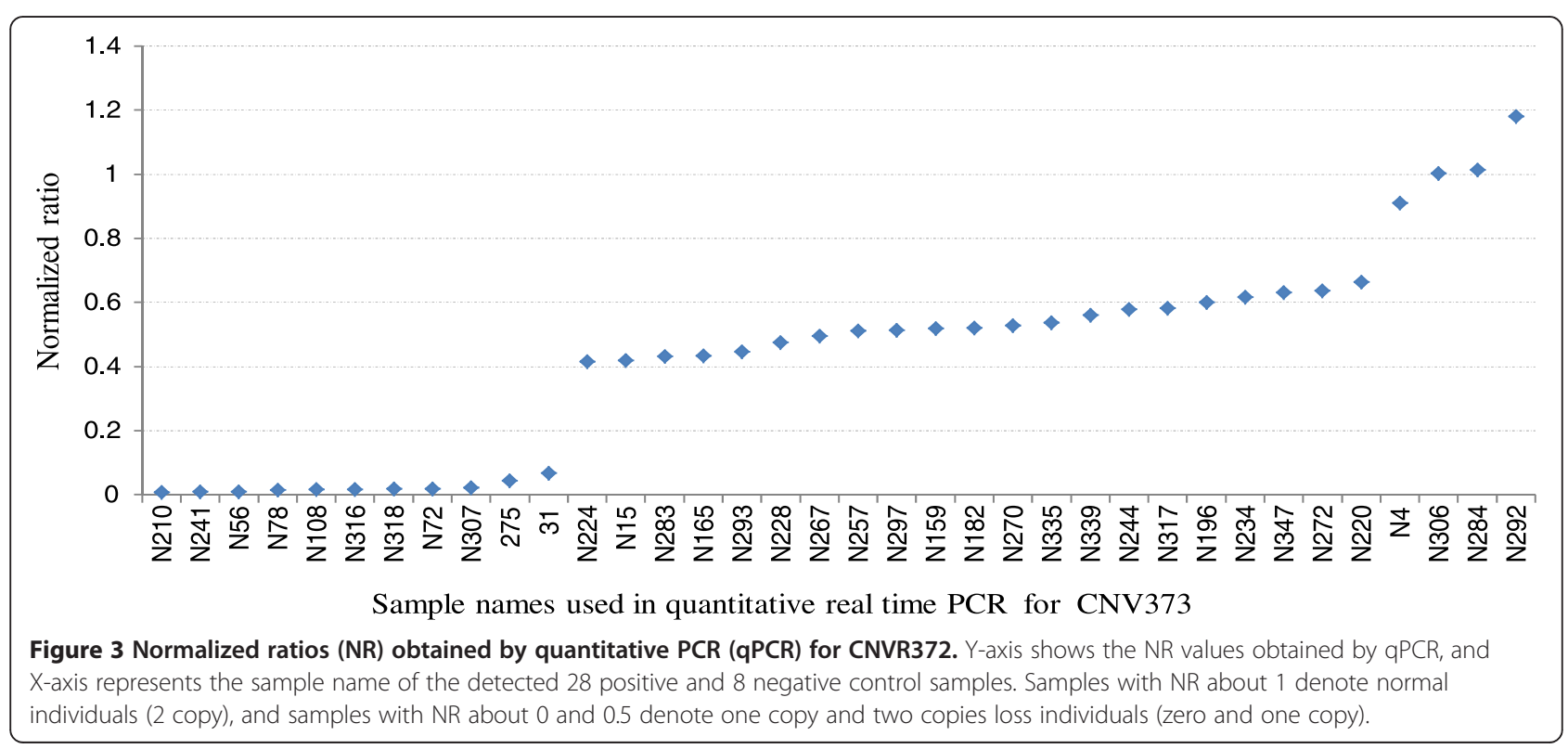


average number of genes per $\mathrm{Mb}$ of the $382 \mathrm{CNVRs}$ is 15.32, which is larger than that on the whole genome (9.05) according to the Sscrofa 9.0 assembly in Ensembl (http://asia.ensembl.org/). It has been suggested that $\mathrm{CNVs}$ are located preferably in gene-poor regions [40,41], probably because CNVs present in gene-rich regions may be deleterious and therefore removed by purifying selection [42]. In contrast to it, the larger number of genes in the identified CNVRs probably reflects the fact that the Porcine SNP60 BeadChip used in this study is biased toward the gene-rich regions. Functional analyses, such as GO, pathway and overlapping with QTLs in pig QTLdb, suggest that these genes entail a great variety of molecular functions, making them a promising resource for exploring the genetic basis of phenotypic variation within and among breeds. Especially, consistent with CNV studies in human, mouse, cattle, and dog $[1,5,7,21]$, some of the enriched GO terms, such as drug detoxification, innate and adaptive immunity, and receptor and signal recognition, are also present in pigs. Conservation of some CNVs across different species suggests that selective pressure may tend to favor specific gene dosage changes, and genes involved in these CNVs may affect the adaptability and fitness of an organism in response to external pressures [1].

Most of our CNVRs were reported for the first time. In order to confirm these novel CNVRs, we selected 18 CNVRs for validation by qPCR, and 12 of them (66.6\%) were validated. The confirmed rate is higher than most of previously reported, such as Fadista et al. [9] in pigs $(50 \%)$ and Hou et al. [8] in cattle (60\%) but a little lower than that reported by Ramayo-Caldas et al. [10] in pigs (71\%). In the study of Ramayo-Caldas et al. [10], the CNVRs selected to be validated were detected by at least two programs and were of high frequency, whereas CNVRs selected to be validated herein were detected by one program, with low to high frequencies. The average proportion of the confirmed positive samples of the 12 validated CNVRs were $92.69 \%$, demonstrating that for most of the positive samples qPCR experiments agreed well with the PennCNV prediction, whereas the false negative rate in the negative samples were rather high, with an average of $31.82 \%$. False-negative identification is common in $\mathrm{CNV}$ detection, and has been reported previously $[9,10,21]$. It can be explained by the stringent criteria of $\mathrm{CNV}$ detection, i.e., containing three or more consecutive SNPs and presented in at least two individuals, which were applied in order to minimize the false-positive, and thus resulted in high false-negative rate inevitably.

Eight out of the 12 successfully validated CNVRs contain functionally important genes. Three of them (CNVR_ID: 22, 276 and 373) include genes of olfactory receptors (ORs) family. ORs are involved in odorant recognition and form the largest mammalian protein superfamily [43]. Many studies in human and other mammals also indicate that the OR genomic loci are frequently affected by CNVs $[2,4,5,40,43,44]$. The qPCR assays revealed that all of the three CNVRs could be confirmed by two pairs of primers. The other five CNVRs (CNVR_No 20, 259, 314, 325, 344) contain many important immune-related and basic metabolic genes, including TNF receptor-associated factor 1 (TRAF1), EGF containing fibulin-like extracellular matrix protein 2 (EFEMP2), D4, zinc and double PHD fingers family 2 (DPF2), CD4 molecule (CD4), glyceraldehyde-3phosphate dehydrogenase $(G A P D H)$, ferritin, light polypeptide (FTL) and interferon regulatory factor 3 (IRF3). The functions of these genes have been reported in pig and other species, and their detailed information was showed in Table $S 9$ of the Additional file 1. In particular, $C D 4$ was the first time to be found to have copy number change not only in pigs but in human and other animals. Considering the important function of genes in them, the five CNVRs are worth to be further studied.

The Porcine SNP60 BeadChip was originally developed for high-throughput SNP genotyping for genomewide association studies. Although CNV detection is also feasible with such panel, it is impaired by low marker density, non-uniform distribution of SNPs along pig chromosomes and lack of non-polymorphic probes specifically designed for CNV identification [45]. Hence, only large CNVRs are expected to be assessed with the Porcine SNP60 array. Furthermore, the Sscrofa 9 assembly, with $4 \times$ sequence depth across the genome, is still in incomplete status, which makes it difficult to determine the boundaries of CNVRs. Accordingly, multiple, neighboring, and discrete $\mathrm{CNV}$ events could trigger a larger call by PennCNV, leading to an over-estimation of the CNV size. Therefore, it is quite possible that the qPCR primers used to validate the CNVRs were designed beyond the boundaries of the CNVRs. Besides these aspects, factors, such as potential SNPs and small indels undetected so far, could also influence the hybridization of the qPCR primers in some animals, resulting in unstable quantification values or reducing primer efficiency.

Many gene families, including olfactory receptor, solute carrier, cytochrome P450, MHC and interleukin, which had been reported to be influenced by CNVs in human and other mammals $[10,44,46]$, were also found to be in the CNVRs of this study. Additionally, by converting the pig Ensembl gene IDs to their orthologous human gene, we checked whether they have been included in the Human Database of Genomic Variants (http://projects.tcag.ca/variation/). It turned out that 590 genes (Additional file 1: Table S2), a remarkably high 
proportion $(40.19 \%)$ of all the total number genes in the identified CNVRs, were reported to be influenced by CNVs in human.

\section{Conclusions}

We have performed a genome-wide CNV detection based on the Porcine SNP60 genotyping data of 474 pigs and provided the highest resolution $\mathrm{CNV}$ map in the pig genome so far. A total of 382 CNVRs were identified. Validating of 18 CNVRs of these CNVRs by qPCR assays produced a high rate $(66.67 \%)$ of confirmation. We conclude that the currently available genome-wide SNP assays can capture CNVs efficiently. However, it should be noticed that only large CNVRs are expected to be identified using this SNP panel and the number of CNVs identified in this study is likely to be a gross underestimation of the true number of CNVs in the pig genome. Follow-up studies, using improved SNP arrays as well as other technologies, such as $\mathrm{CGH}$ arrays and next-generation sequencing [47], should be carried out to attain highresolution CNV map. Association studies between CNVs and diseases have become popular in human [15-17], and have begun in animal as well [48]. Findings in our study would provide meaningful genomic variation information for association studies between $\mathrm{CNV}$ and economically important phenotypes of pigs in the future.

\section{Methods}

\section{Animal resource}

The animals initially used in this study were composed of 1,017 pigs from four populations with different genetic background, including 500 Yorkshire pigs, 85 Landrace pigs, 96 Songliao Black pigs, and 336 Duroc $\times$ Erhualian crossbred pigs. Songliao Black is a breed derived from cross of Landrace, Duroc and Min pigs. The Duroc $x$ Erhualian crossbred was formed by crossing eight Duroc boars with 18 Erhualian sows. Both Min pigs and Erhualian pigs are Chinese indigenous breeds.

\section{SNP array genotyping and quality control}

Genomic DNA samples were extracted from ear tissue of all pigs using a standard phenol/chloroform method. All DNA samples were analyzed by spectrophotometry and agarose gel electrophoresis. The genotyping platform used was Infinium II Multisample assay (Illumina Inc.). SNP arrays were scanned using iScan (Illumina Inc.) and analyzed using BeadStudio (Version 3.2.2, Illumina, Inc.). The whole procedure for collection of the ear tissue samples was carried out in strict accordance with the protocol approved by the Animal Welfare Committee of China Agricultural University (Permit number: DK996).

In order to exclude poor-quality DNA samples and decrease potential false-positive CNVs, quality control was performed according to the following procedures. The genome-wide intensity signal must have as little noise as possible. Only those samples with standard deviation of normalized intensity (Log $\mathrm{R}$ ratio, LRR) $<0.30$ and $\mathrm{B}$ allele frequency (BAF) drift $<0.01$ were included. Since wave artifacts roughly correlating with GC content resulting from hybridization bias of low full-length DNA quantity could interfere with accurate inference of CNVs [37], only samples in which the GC wave factor of LRR less than 0.05 were accepted. Finally, 474 samples (119 Yorkshire pigs, 13 Landrace pigs, 15 Songliao Black pigs and 327 Duroc $\times$ Erhualian crossbred pigs) with highquality genotyping (average call rate $99.67 \%$ ) out of 1,017 samples were remained for CNV detection after quality control.

\section{Identification of pig CNVs}

The PennCNV software [27] was applied to identify pig CNVs in this study. This algorithm incorporates multiple sources of information, including total signal intensity (LRR) and allelic intensity ratio (BAF) at each SNP marker, the distance between neighboring SNPs, the population frequency of $\mathrm{B}$ allele (PFB) of SNPs, and the pedigree information where available [27]. Both LRR and BAF were exported from BeadStudio (Illumina Inc.) given the default clustering file for each SNP. The PFB file was calculated based on the BAF of each marker. The SNPs physical positions on chromosomes were derived from the swine genome sequence assembly (9.0) (http://www.ensembl.org/Sus_scrofa/Info/ Index). Furthermore, PennCNV also integrates a computational approach by fitting regression models with GC content to overcome "genomic waves". The pig gcmodel file was generated by calculating the GC content of the $1 \mathrm{Mb}$ genomic region surrounding each marker $(500 \mathrm{~kb}$ each side) and the genomic waves were adjusted using the -gcmodel option. Although many of the samples had pedigree information initially, most of trio information was unavailable after quality control. So, pedigree/trio information was not incorporated into the analyses.

In this study, CNV was inferred with two criteria: first, it must contain three or more consecutive SNPs, and second it must be present in at least two individuals. Finally, CNVs regions (CNVRs) were determined by aggregating overlapping CNVs identified across all samples according to the criteria proposed by Redon et al. [2].

Due to density limitation of SNPs on chromosome X, i. e. about $86 \mathrm{~kb}$ of averaged SNP interval, which is two folds of the average interval across whole genome, CNVs detected on chromosome $\mathrm{X}$ might have high false-positive rate and were excluded from further analyses in our study.

\section{Gene contents and functional annotation}

Gene contents in the identified CNVRs were retrieved from the Ensembl Genes 64 Database using the BioMart (http://www.biomart.org/) data management system 
[28]. To provide insight into the functional enrichment of the CNVs, functional annotation was performed with the DAVID bioinformatics resources 6.7 (http://david. abcc.ncifcrf.gov/summary.jsp) [31] for Gene Ontology (GO) terms [29] and Kyoto Encyclopedia of Genes and Genomes (KEGG) [30] pathway analyses. Since only a limited number of genes in the pig genome have been annotated, we firstly converted the pig Ensembl gene IDs to orthologous mouse Ensembl gene IDs by BioMart (Additional file 1: Table S8), then carried out the GO and pathway analyses. Statistical significance was assessed by using $P$ value of a modified Fisher's exact test and Benjamini correction for multiple testing.

\section{Quantitative real time PCR}

Quantitative real time PCR (qPCR) was used to validate 18 CNVRs chosen from the 382 CNVRs detected in the study. We used the $2^{-\Delta \Delta \mathrm{Ct}}$ method for relative quantification of CNVs [49], which compares the $\Delta C_{t}$ (cycle threshold $\left(C_{t}\right)$ of the target region minus $C_{t}$ of the control region) value of samples with CNV to the $\Delta C_{t}$ of a calibrator without $\mathrm{CNV}$. The glucagon gene (GCG) is highly conserved between species and has been approved to have a single copy in animals $[10,50]$. So, one segment of it was chosen as control region. Primers (Table S6 of Additional file 1) were designed with the Primer3 web tool (http://frodo.wi.mit. edu/primer3/). Moreover, the UCSC In-Silico PCR tool (http://genome.ucsc.edu/cgi-bin/hgPcr?command=start) was used for in silico specificity analysis [51]. Prior to performing the copy number assay, we generated standard curves for the primers of target and control regions to determine their PCR efficiencies. To ensure the same amplification efficiencies between target and control primers, the PCR efficiencies for all primers used in the study were required to be 1.95-2.10.

All qPCR were carried out using LightCycler ${ }^{\circledR} 480$ SYBR Green I Master on Roche LightCycler ${ }^{\circledR} 480$ instrument following the manufacturer's guidelines and cycling conditions. The reactions were carried out in a 96-well plate in $20 \mu \mathrm{l}$ volume, containing $10 \mu \mathrm{l}$ Blue-SYBR-Green mix, $1 \mu \mathrm{l}$ forward and reverse primers $(10 \mathrm{pM} / \mu \mathrm{l})$ and $1 \mu \mathrm{l}$ 20ng/ $\mu$ l genomic DNA. Each sample was analyzed in duplicates. The second derivative maximum algorithm included within the instrument software was used to determine cycle threshold $\left(C_{t}\right)$ values for each region.

\section{Additional files}

Additional file 1: Table S1. Information of 382 identified CNVRs and their distributions in the four populations. Additional file 1: Table S2. Information of genes in the identified CNVRs and their comparison with Human Database of Genomic Variants. Additional file 1: Table S3. Gene ontology (GO) analyses of genes in the identified CNVRs. Additional file 1: Table S4. Pathway analyses of genes in the identified CNVRs. Additional file 1: Table S5. Previously reported QTLs overlapped with identified CNVRs. Additional file 1: Table S6.
Information and the primers used in qPCR analyses of the 18 CNVRs chosen to be validated. Additional file 1: Table S7. Comparison between identified CNVRs and those of previous reports of pig CNVs. Additional file 1: Table S8. Pig Ensembl gene IDs and their orthologous mouse IDs. Additional file 1: Table S9. Functions of the genes validated to be copy number variable by qPCR assay [52-65].

\section{Competing interests}

The authors declare that they have no competing interests.

\section{Acknowledgements}

The authors appreciate the financial support provided by the National High Technology Research and Development Program of China (863 Program 2011AA100302), the National Major Special Project of China on New Varieties Cultivation for Transgenic Organisms (2009ZX08009-146B), the National Natural Science Foundations of China (30972092), the Natural Science Foundations of Beijing (6102016), New-Century Training Program Foundation for the Talents by the State Education Commission of China (NETC-10-0783) and Scientific Research Foundation for the Returned Overseas Chinese Scholars of State Education Ministry.

\section{Author details}

${ }^{1}$ Key Laboratory of Animal Genetics, Breeding and Reproduction, Ministry of Agriculture, National Engineering Laboratory for Animal Breeding, College of Animal Science and Technology, China Agricultural University, Beijing 100193, China. ${ }^{2}$ Shandong Provincial Key Laboratory of Animal Disease Control and Breeding, Institute of Animal Science and Veterinary Medicine, Shandong Academy of Agricultural Sciences, Jinan 250100, China.

\section{Authors' contributions}

WJ carried out gene annotation, experimental validations and wrote the manuscript. JJ carried out computational analysis. $L$ and ZQ conceived of the study and led in its design and coordination. JL, FW and DX contributed to the sample genotyping, data analysis and interpretation of data. All authors read and approved the final manuscript.

Received: 1 January 2012 Accepted: 22 June 2012

Published: 22 June 2012

\section{References}

1. Feuk L, Carson AR, Scherer SW: Structural variation in the human genome. Nat Rev Genet 2006, 7(2):85-97.

2. Redon $R$, Ishikawa $S$, Fitch $K R$, Feuk L, Perry GH, Andrews TD, Fiegler $H$, Shapero MH, Carson AR, Chen W, Cho EK, Dallaire S, Freeman JL, González JR, Gratacòs M, Huang J, Kalaitzopoulos D, Komura D, MacDonald JR, Marshall CR, Mei R, Montgomery L, Nishimura K, Okamura K, Shen F, Somerville MJ, Tchinda J, Valsesia A, Woodwark C, Yang F, Zhang J, Zerjal T, Zhang J, Armengol L, Conrad DF, Estivill X, Tyler-Smith C, Carter NP, Aburatani $\mathrm{H}$, Lee $\mathrm{C}$, Jones KW, Scherer SW, Hurles ME: Global variation in copy number in the human genome. Nature 2006, 444(7118):444-454.

3. Komura D, Shen F, Ishikawa S, Fitch KR, Chen W, Zhang J, Liu G, Ihara S, Nakamura H, Hurles ME, Lee C, Scherer SW, Jones KW, Shapero MH, Huang J, Aburatani $\mathrm{H}$ : Genome-wide detection of human copy number variations using high-density DNA oligonucleotide arrays. Genome Res 2006, 16(12):1575-1584.

4. Cutler G, Marshall LA, Chin N, Baribault H, Kassner PD: Significant gene content variation characterizes the genomes of inbred mouse strains. Genome Res 2007, 17(12):1743-1745.

5. Graubert TA, Cahan P, Edwin D, Selzer RR, Richmond TA, Eis PS, Shannon WD, Li X, McLeod HL, Cheverud JM, Ley TJ: A high-resolution map of segmental DNA copy number variation in the mouse genome. PLOS Genet 2007, 3(1):e3.

6. Guryev V, Saar K, Adamovic T, Verheul M, van Heesch SA, Cook S, Pravenec M, Aitman T, Jacob H, Shull JD, Hubner N, Cuppen E: Distribution and functional impact of DNA copy number variation in the rat. Nat Genet 2008, 40(5):538-545.

7. Liu GE, Hou Y, Zhu B, Cardone MF, Jiang L, Cellamare A, Mitra A, Alexander LJ, Coutinho LL, Dell'Aquila ME, Gasbarre LC, Lacalandra G, Li RW, Matukumalli LK, Nonneman D, Regitano LC, Smith TP, Song J, Sonstegard TS, Van Tassell CP, Ventura M, Eichler EE, McDaneld TG, Keele JW: Analysis 
of copy number variations among diverse cattle breeds. Genome Res 2010, 20(5):693-703.

8. Hou Y, Liu GE, Bickhart DM, Cardone MF, Wang K, Kim ES, Matukumalli LK, Ventura M, Song J, VanRaden PM, Sonstegard TS, Van Tassell CP: Genomic characteristics of cattle copy number variations. BMC Genomics 2011, 12(1):127.

9. Fadista J, Nygaard M, Holm LE, Thomsen B, Bendixen C: A snapshot of CNVs in the pig genome. PLoS One 2008, 3(12):e3916.

10. Ramayo-Caldas Y, Castelló A, Pena RN, Alves E, Mercadé A, Souza CA, Fernández Al, Perez-Enciso M, Folch JM: Copy number variation in the porcine genome inferred from a 60 k SNP BeadChip. BMC Genomics 2010, 11(1):593.

11. Wang X, Nahashon S, Feaster TK, Bohannon-Stewart A, Adefope N: An initial map of chromosomal segmental copy number variations in the chicken. BMC Genomics 2010, 11(1):351.

12. Henrichsen $C N$, Chaignat $E$, Reymond A: Copy number variants, diseases and gene expression. Hum Mol Genet 2009, 18(R1):R1-R8.

13. Zhang F, Gu W, Hurles ME, Lupski JR: Copy number variation in human health, disease, and evolution. Annu Rev Genomics Hum Genet 2009, 10:451-481.

14. McCarroll SA, Altshuler DM: Copy-number variation and association studies of human disease. Nat Genet 2007, 39:S37-S42.

15. Bronstad I, Wolff A, Lovas K, Knappskog P, Husebye E: Genome-wide copy number variation (CNV) in patients with autoimmune Addison's disease. BMC Med Genet 2011, 12(1):111

16. Ionita-Laza I, Rogers AJ, Lange C, Raby BA, Lee C: Genetic association analysis of copy-number variation (CNV) in human disease pathogenesis. Genomics 2009, 93(1):22-26.

17. Sebat J, Lakshmi B, Malhotra D, Troge J, Lese-Martin C, Walsh T, Yamrom B, Yoon S, Krasnitz A, Kendall J, Leotta A, Pai D, Zhang R, Lee YH, Hicks J, Spence SJ, Lee AT, Puura K, Lehtimäki T, Ledbetter D, Gregersen PK, Bregman J, Sutcliffe JS, Jobanputra V, Chung W, Warburton D, King MC, Skuse D, Geschwind DH, Gilliam TC, Ye K, Wigler M: Strong association of de novo copy number mutations with autism. Science 2007, 316(5823):445-449.

18. Marklund S, Kijas J, Rodriguez-Martinez H, Rönnstrand L, Funa K, Moller M, Lange D, Edfors-Lilja I, Andersson L: Molecular basis for the dominant white phenotype in the domestic pig. Genome Res 1998, 8(8):826-833.

19. Giuffra E, Törnsten A, Marklund S, Bongcam-Rudloff E, Chardon P, Kijas JMH, Anderson SI, Archibald AL, Andersson L: A large duplication associated with dominant white color in pigs originated by homologous recombination between LINE elements flanking KIT. Mamm Genome 2002, 13(10):569-577.

20. Wright D, Boije H, Meadows JRS: Bed'hom B, Gourichon D, Vieaud A, Tixier-Boichard M, Rubin CJ, Imsland F, Hallböök F, Andersson L: Copy number variation in intron 1 of SOX5 causes the Pea-comb phenotype in chickens. PLoS Genet 2009, 5(6):e1000512.

21. Nicholas TJ, Cheng Z, Ventura M, Mealey K, Eichler EE, Akey JM: The genomic architecture of segmental duplications and associated copy number variants in dogs. Genome Res 2009, 19(3):491-499.

22. Nicholas TJ, Baker C, Eichler EE, Akey JM: A high-resolution integrated map of copy number polymorphisms within and between breeds of the modern domesticated dog. BMC Genomics 2011, 12:414.

23. Peiffer DA, Le JM, Steemers FJ, Chang W, Jenniges T, Garcia F, Haden K, Li J, Shaw CA, Belmont J, Cheung SW, Shen RM, Barker DL, Gunderson $\mathrm{KL}$ : High-resolution genomic profiling of chromosomal aberrations using Infinium whole-genome genotyping. Genome Res 2006, 16(9):1136-1148

24. Winchester $L$, Yau C, Ragoussis J: Comparing CNV detection methods for SNP arrays. Brief Funct Genomic Proteomic 2009, 8(5):353-366.

25. Bae JS, Cheong HS, Kim LH, NamGung S, Park TJ, Chun JY, Kim JY, Pasaje CF, Lee JS, Shin HD: Identification of copy number variations and common deletion polymorphisms in cattle. BMC Genomics 2010, 11:232.

26. Wang K, Chen Z, Tadesse MG, Glessner J, Grant SFA, Hakonarson H, Bucan M, Li M: Modeling genetic inheritance of copy number variations. Nucleic Acids Res 2008, 36(21):e138.

27. Wang K, Li M, Hadley D, Liu R, Glessner J, Grant SFA, Hakonarson H, Bucan M: PennCNV: an integrated hidden Markov model designed for high-resolution copy number variation detection in whole-genome SNP genotyping data. Genome Res 2007, 17(11):1665-1674.
28. Smedley D, Haider S, Ballester B, Holland R, London D, Thorisson G, Kasprzyk A: BioMart-biological queries made easy. BMC Genomics 2009, 10(1):22.

29. Ashburner M, Ball CA, Blake JA, Botstein D, Butler H, Cherry JM, Davis AP, Dolinski K, Dwight SS, Eppig JT, Harris MA, Hill DP, Issel-Tarver L, Kasarskis A, Lewis S, Matese JC, Richardson JE, Ringwald M, Rubin GM, Sherlock G: Gene Ontology: tool for the unification of biology. Nat Genet 2000, 25(1):25-29.

30. Kanehisa M, Goto S, Furumichi M, Tanabe M, Hirakawa M: KEGG for representation and analysis of molecular networks involving diseases and drugs. Nucleic Acids Res 2010, 38(suppl 1):D355-D360.

31. Da Wei Huang BTS, Lempicki RA: Systematic and integrative analysis of large gene lists using DAVID bioinformatics resources. Nat Protoc 2008, 4(1):44-57.

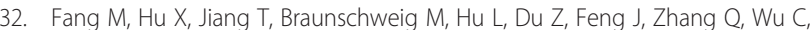
$\mathrm{Li} N$ : The phylogeny of Chinese indigenous pig breeds inferred from microsatellite markers. Anim Genet 2005, 36(1):7-13.

33. Wang JY, Guo JF, Zhang Q, Hu HM, Lin HC, Wang C, Zhang Y, Wu Y: Genetic Diversity of Chinese Indigenous Pig Breeds in Shandong Province Using Microsatellite Markers. Asian-Aust J Anim Sci 2011, 24(1):28-36.

34. Megens HJ, Crooijmans Rp, San Cristobal M, Hui X, Li N, Groenen MA: Biodiversity of pig breeds from China and Europe estimated from pooled DNA samples: differences in microsatellite variation between two areas of domestication. Genet Sel Evol 2008, 40(1):103-128.

35. Fang $M$, Andersson L: Mitochondrial diversity in European and Chinese pigs is consistent with population expansions that occurred prior to domestication. Proceedings of the Royal Society B: Biological Sciences 2006, 273(1595):1803-1810.

36. Pique-Regi R, Monso-Varona J, Ortega A, Seeger RC, Triche TJ, Asgharzadeh S: Sparse representation and Bayesian detection of genome copy number alterations from microarray data. Bioinformatics 2008, 24(3):309-318.

37. Diskin SJ, Li M, Hou C, Yang S, Glessner J, Hakonarson H, Bucan M, Maris JM, Wang K: Adjustment of genomic waves in signal intensities from wholegenome SNP genotyping platforms. Nucleic Acids Res 2008, 36(19):e126.

38. Matsuzaki H, Wang PH, Hu J, Rava R, Fu GK: High resolution discovery and confirmation of copy number variants in 90 Yoruba Nigerians. Genome Biol 2009, 10(11):R125.

39. Eichler EE: Widening the spectrum of human genetic variation. Nat Genet 2006, 38(1):9-11.

40. Conrad DF, Andrews TD, Carter NP, Hurles ME, Pritchard JK: A highresolution survey of deletion polymorphism in the human genome. Nat Genet 2006, 38(1):75-81.

41. Freeman $\mathrm{J}$, Perry $\mathrm{GH}$, Feuk $\mathrm{L}$, Redon $\mathrm{R}$, McCarroll SA, Altshuler DM, Aburatani H, Jones KW, Tyler-Smith C, Hurles ME, Carter NP, Scherer SW, Lee $\mathrm{C}$ : Copy number variation: new insights in genome diversity. Genome Res 2006, 16(8):949-961.

42. Conrad DF, Hurles ME: The population genetics of structural variation. Nat Genet 2007, 39:S30-S36.

43. Hasin Y, Olender T, Khen M, Gonzaga-Jauregui C, Kim PM, Urban AE, Snyder M, Gerstein MB, Lancet D, Korbel JO: High-resolution copy-number variation map reflects human olfactory receptor diversity and evolution. PLoS Genet 2008, 4(11):e1000249.

44. Young JM, Endicott RLM, Parghi SS, Walker M, Kidd JM, Trask BJ: Extensive copy-number variation of the human olfactory receptor gene family. Am J Hum Genet 2008, 83(2):228-242.

45. Ramos AM, Crooijmans RP, Affara NA, Amaral AJ, Archibald AL, Beever JE, Bendixen C, Churcher C, Clark R, Dehais P, Hansen MS, Hedegaard J, Hu ZL, Kerstens HH, Law AS, Megens HJ, Milan D, Nonneman DJ, Rohrer GA, Rothschild MF, Smith TP, Schnabel RD, Van Tassell CP, Taylor JF, Wiedmann RT, Schook LB, Groenen MA: Design of a high density SNP genotyping assay in the pig using SNPs identified and characterized by next generation sequencing technology. PLoS One 2009, 4(8):e6524.

46. Bickhart DM, Hou Y, Schroeder SG, Alkan C, Cardone MF, Matukumalli LK Song J, Schnabel RD, Ventura M, Taylor JF, Garcia JF, Van Tassell CP, Sonstegard TS, Eichler EE, Liu GE: Copy number variation of individual cattle genomes using next-generation sequencing. Genome res 2012, 22(4):778-790.

47. Castle JC, Biery M, Bouzek H, Xie T, Chen R, Misura K, Jackson S, Armour CD, Johnson JM, Rohl CA, Raymond CK: DNA copy number, including telomeres and mitochondria, assayed using next-generation sequencing. BMC Genomics 2010, 11(1):244.

48. Liu GE, Brown T, Hebert DA, Cardone MF, Hou Y, Choudhary RK, Shaffer J, Amazu C, Connor EE, Ventura M, Gasbarre LC: Initial analysis of copy 
number variations in cattle selected for resistance or susceptibility to intestinal nematodes. Mamm Genome 2011, 22:111-121.

49. Livak KJ, Schmittgen TD: Analysis of relative gene expression data using real-time quantitative PCR and the 2-[Delta][Delta] CT method. Methods 2001, 25(4):402-408.

50. Ballester M, Castelló A, Ibáez E, Sánchez A, Folch JM: Real-time quantitative PCR-based system for determining transgene copy number in transgenic animals. Biotechniques 2004, 37(4):610-613.

51. Karolchik D, Kuhn RM, Baertsch R, Barber GP, Clawson H, Diekhans M, Giardine B, Harte RA, Hinrichs AS, Hsu F, Kober KM, Miller W, Pedersen JS, Pohl A, Raney BJ, Rhead B, Rosenbloom KR, Smith KE, Stanke M, Thakkapallayil A, Trumbower H, Wang T, Zweig AS, Haussler D, Kent WJ: The UCSC genome browser database: 2008 update. Nucleic Acids Res 2008, 36(suppl 1):D773-D779.

52. Kurreeman FA, Goulielmos GN, Alizadeh BZ, Rueda B, Houwing-Duistermaat J, Sanchez E, Bevova M, Radstake TR, Vonk MC, Galanakis E, Ortego N, Verduyn W, Zervou Ml, Roep BO, Dema B, Espino L, Urcelay E, Boumpas DT, van den Berg LH, Wijmenga C, Koeleman BP, Huizinga TW, Toes RE, Martin J, AADEA Group, SLEGEN Consortium: The TRAF1-C5 region on chromosome $9 \mathrm{q} 33$ is associated with multiple autoimmune diseases. Ann Rheum Dis 2010, 69(4):696-699.

53. Jawaheer D, Seldin MF, Amos Cl, Chen WV, Shigeta R, Monteiro J, Kern M, Criswell LA, Albani S, Nelson JL, Clegg DO, Pope R, Schroeder HW Jr, Bridges SL Jr, Pisetsky DS, Ward R, Kastner DL, Wilder RL, Pincus T, Callahan LF, Flemming D, Wener MH, Gregersen PK: A genomewide screen in multiplex rheumatoid arthritis families suggests genetic overlap with other autoimmune diseases. Am J Hum Genet 2001, 68(4):927-936.

54. Redler S, Brockschmidt FF, Forstbauer L, Giehl KA, Herold C, Eigelshoven S, Hanneken S, De Weert J, Lutz G, Wolff H, Kruse R, Blaumeiser B, Böhm M, Becker T, Nöthen MM, Betz RC: The TRAF1/C5 locus confers risk for familial and severe alopecia areata. Br J Dermatol 2010, 162(4):866-869.

55. Renard M, Holm T, Veith R, Callewaert BL, Adès LC, Baspinar O, Pickart A, Dasouki M, Hoyer J, Rauch A, Trapane P, Earing MG, Coucke PJ, Sakai LY, Dietz HC, De Paepe AM, Loeys BL: Altered TGF $\beta$ signaling and cardiovascular manifestations in patients with autosomal recessive cutis laxa type I caused by fibulin-4 deficiency. Eur J Hum Genet 2010 18(8):895-901.

56. Zhang W, Xu C, Bian C, Tempel W, Crombet L, MacKenzie F, Min J, Liu Z, Qi $C$ : Crystal structure of the Cys2His2-type zinc finger domain of human DPF2. Biochem Biophys Res Commun 2010, 413(1):58-61.

57. Davis CB, Littman DR: Thymocyte lineage commitment: is it instructed to stochastic? Curr Opin Immunol 1994, 6(2):266-272.

58. Killeen N, Davis CB, Chu K, Crooks MEC, Sawada S, Scarborough JD, Boyd KA, Stuart SG, Xu H, Littman DR: CD4 function in thymocyte differentiation and T cell activation. Philosophical Transactions. Biological Sciences 1993, 25-34.

59. Butterfield DA, Hardas SS, Lange MLB: Oxidatively modified glyceraldehyde-3-phosphate dehydrogenase (GAPDH) and Alzheimer's disease: many pathways to neurodegeneration. J Alzheimers Dis 2010, 20(2):369-393.

60. Chuang DM, Hough C, Senatorov W: Glyceraldehyde-3-phosphate dehydrogenase, apoptosis, and neurodegenerative diseases. Annu Rev Pharmacol Toxicol 2005, 45:269-290.

61. Vidal R, Ghetti B, Takao M, Brefel-Courbon C, Uro-Coste E, Glazier BS, Siani V, Benson MD, Calvas P, Miravalle L, Rascol O, Delisle MB: Intracellular ferritin accumulation in neural and extraneural tissue characterizes a neurodegenerative disease associated with a mutation in the ferritin light polypeptide gene. J Neuropathol Exp Neurol 2004, 63(4):363-380.

62. Girelli D, Corrocher R, Bisceglia L, Olivieri O, De Franceschi L, Zelante L, Gasparini P: Molecular basis for the recently described hereditary hyperferritinemia-cataract syndrome: a mutation in the iron-responsive element of ferritin L-subunit gene (the" Verona mutation"). Blood 1995, 86(11):4050-4053.

63. Sato $M$, Taniguchi $T$, Tanaka N: The interferon system and interferon regulatory factor transcription factors-studies from gene knockout mice. Cytokine Growth Factor Rev 2001, 12(2-3):133-142.

64. Taniguchi T, Takaoka A: The interferon-[alpha]/[beta] system in antiviral responses: a multimodal machinery of gene regulation by the IRF family of transcription factors. Curr Opin Immunol 2002, 14(1):111-116.
65. Wellcome Trust Case Control Consortium: Genome-wide association study of 14,000 cases of seven common diseases and 3,000 shared controls. Nature 2007, 447(7145):661-678.

\section{doi:10.1186/1471-2164-13-273}

Cite this article as: Wang et al:: A genome-wide detection of copy number variations using SNP genotyping arrays in swine. BMC Genomics 2012 13:273.

\section{Submit your next manuscript to BioMed Central and take full advantage of:}

- Convenient online submission

- Thorough peer review

- No space constraints or color figure charges

- Immediate publication on acceptance

- Inclusion in PubMed, CAS, Scopus and Google Scholar

- Research which is freely available for redistribution 